\title{
Ein kurzes Fazit
}

Städtebau bildet die Klammer zwischen Stadtplanung und Architektur, indem er den planerischen Rahmen konkretisiert und das einzelne Gebäude in den Kontext einbettet. Vor dem Hintergrund der skizzierten vielschichtigen Herausforderungen ist der Städtebau eine wirkliche „Königsdisziplin“, die einen entscheidenden Einfluss auf die Lebensqualität in unseren Quartieren, Städten und Regionen hat.

Jede Zeit hat ihre eigenen inhaltlichen Schwerpunkte im Verständnis von Städtebau gesetzt und mit entsprechenden Leitbildern versucht, die jeweiligen Probleme zu lösen. Städtebau ist heute - mehr als in den vergangenen Phasen der Stadtentwicklung - ein prozesshaftes Vorgehen mit dem Ziel, ein überzeugendes Produkt im Sinne der gebauten Umwelt herzustellen. Dabei werden gute städtebauliche Lösungen und überzeugende Konzepte dann erzielt, wenn nicht nur Architekten, Stadtplaner und Ingenieure beteiligt sind, sondern auch Politiker, institutionelle und private Investoren, Kreative, Soziologen, Klimaforscher, Lichtdesigner, Eventmanager und mehr denn je die Stadtgesellschaft selbst. Städtebau erfordert die Auseinandersetzung mit dem äußerst komplexen Gegenstand der Stadt, aber auch die Bereitschaft, sich auf diese Komplexität einzulassen und an dem jeweiligen Ort um die richtige Lösung zu ringen. 